\title{
Heat and moisture exchangers (HMEs) and heated humidifiers (HHs) in adult critically ill patients: a systematic review, meta-analysis and meta-regression of randomized controlled trials
}

\author{
Maria Vargas ${ }^{1 *}$ (D), Davide Chiumello², Yuda Sutherasan ${ }^{3}$, Lorenzo Ball $^{4}$, Antonio M. Esquinas $^{5}$, Paolo Pelosi ${ }^{4}$ \\ and Giuseppe Servillo ${ }^{1}$
}

\begin{abstract}
Background: The aims of this systematic review and meta-analysis of randomized controlled trials are to evaluate the effects of active heated humidifiers (HHs) and moisture exchangers (HMEs) in preventing artificial airway occlusion and pneumonia, and on mortality in adult critically ill patients. In addition, we planned to perform a meta-regression analysis to evaluate the relationship between the incidence of artificial airway occlusion, pneumonia and mortality and clinical features of adult critically ill patients.

Methods: Computerized databases were searched for randomized controlled trials (RCTs) comparing HHs and HMEs and reporting artificial airway occlusion, pneumonia and mortality as predefined outcomes. Relative risk (RR), 95\% confidence interval for each outcome and $P$ were estimated for each outcome. Furthermore, weighted random-effect meta-regression analysis was performed to test the relationship between the effect size on each considered outcome and covariates.

Results: Eighteen RCTs and 2442 adult critically ill patients were included in the analysis. The incidence of artificial airway occlusion ( $R R=1.853 ; 95 \% \mathrm{Cl} 0.792-4.338)$, pneumonia $(R R=932 ; 95 \% \mathrm{Cl} 0.730-1.190)$ and mortality ( $R R=1.023$; 95\% Cl 0.878-1.192) were not different in patients treated with HMEs and HHs. However, in the subgroup analyses the incidence of airway occlusion was higher in HMEs compared with HHs with non-heated wire (RR = 3.776; 95\% Cl 1.560-9.143). According to the meta-regression, the effect size in the treatment group on artificial airway occlusion was influenced by the percentage of patients with pneumonia $(\beta=-0.058 ; p=0.027$; favors HMEs in studies with high prevalence of pneumonia), and a trend was observed for an effect of the duration of mechanical ventilation (MV) ( $\beta=-0.108 ; p=0.054$; favors HMEs in studies with longer MV time).

Conclusions: In this meta-analysis we found no superiority of HMEs and HHs, in terms of artificial airway occlusion, pneumonia and mortality. A trend favoring HMEs was observed in studies including a high percentage of patients with pneumonia diagnosis at admission and those with prolonged MV. However, the choice of humidifiers should be made according to the clinical context, trying to avoid possible complications and reaching the appropriate performance at lower costs.
\end{abstract}

Keywords: Heated humidifiers, Heat and moisture exchangers, Artificial airway occlusion, Pneumonia, Mortality

\footnotetext{
* Correspondence: vargas.maria82@gmail.com

${ }^{1}$ Department of Neurosciences, Reproductive and Odonthostomatological

Sciences, University of Naples "Federico II", Naples, Italy

Full list of author information is available at the end of the article
} 


\section{Background}

Mechanical ventilation (MV) suppresses the mechanisms that heat and moisturize inhaled air. As a consequence, the lack of adequate conditioning may thicken airway secretions, which increases the airway resistance, reduces the gas exchange effectiveness and increases the risk of respiratory infections [1]. For these reasons, gas delivered during MV must be warmed and humidified to avoid serious complications related to dry gases [2]. To date, humidification devices can be divided into active heated humidifiers (HHs), which are devices heated by warm water, and passive devices such as heat and moisture exchangers (HMEs), which capture the heat of exhaled air and release it at the next inspiration [3]. HHs may result in increased airway hydration, decreased incidence of bacterial infection and work of breathing, while HMEs may increase the risk of airway occlusion [4]. In clinical practice, humidification during MV is widely accepted and applied; however, there is lack of consensus on the optimal device to humidify the airways. The aims of this systematic review and meta-analysis of randomized controlled trials are to evaluate the effects of HMEs and HHs in preventing artificial airway occlusion and pneumonia, and on mortality in adult critically ill patients. We planned a priori a subanalysis stratifying the studies according to the type of $\mathrm{HH}$, hypothesizing that $\mathrm{HHs}$ with heated wire could perform differently from those with non-heated wire. In addition, we planned to perform a meta-regression analysis to evaluate the relationship between the incidence of artificial airway occlusion, pneumonia and mortality and clinical features of adult critically ill patients.

\section{Methods}

\section{Data sources and searches}

We aimed to identify all randomized controlled trials (RCTs) comparing HMEs and HHs in adult critically ill patients. We applied standard filters for the identification of RCTs using the MEDLINE and PUBMED search engines (from inception to June 2014), using English language restrictions. Our search included the following keywords: heat and moisture exchangers, heated humidifiers, airway humidification, artificial humidification, artificial airway occlusion, mortality, pneumonia and humans and randomized clinical trial.

\section{Selection of studies}

Trials comparing any type of $\mathrm{HH}$, including systems with heated and non-heated wire, with HMEs in adult critically ill patients were included. We restricted the analysis to RCTs to guarantee control of selection bias. We included only published full papers and excluded abstracts. Study designs containing inadequately adjusted planned co-interventions and crossover trials were excluded. The intervention of interest was the use of $\mathrm{HH}$ and
HME in reducing artificial airway occlusion, pneumonia and mortality. Studies were further divided according to the use of $\mathrm{HH}$ with heated and $\mathrm{HH}$ with non-heated wire to perform the subgroup analysis.

\section{Outcome measures}

The primary outcome was the incidence of artificial airway occlusion; the secondary outcomes were the incidences of pneumonia and mortality.

\section{Data extraction and quality assessment}

Initial selection was performed by two pairs of independent reviewers (MV and DC, PP and YS) screening titles and abstracts. For detailed evaluation, a full-text copy of all studies of possible relevance was retrieved. Data from each study were extracted independently by paired and independent reviewers (LB and DC, PP and YS) using a standardized data abstraction form. Data extracted from the publications were independently checked for accuracy by two other reviewers (GS and AE). Quality assessment of these studies included: (1) use of randomization sequence generation, (2) reporting and type of allocation concealment, (3) blinding, (4) reporting of incomplete outcome data and (5) comparability of the groups at baseline. Quality assessment is reported in Additional file 1. Two reviewers (MV and LB) independently used these criteria to evaluate trial quality. We solved any possible disagreement by consensus in consultation with two other reviewers (GS and AE) if needed.

\section{Qualitative analysis}

A narrative summary approach was used to explore study characteristics and quality indicators in describing variation among studies and to consider possible implications for this in our understanding of the outcomes of the RCTs included in the Cochrane review $[5,6]$.

\section{Quantitative analysis}

The meta-analysis was conducted according to the Preferred Reporting Items for Systematic Reviews and Meta-analyses (PRISMA) guidelines [7]. Meta-analysis was performed with mixed random effect using the DerSimonian and Laird method. Results were graphically represented using forest plot graphs. The relative risk (RR) and $95 \%$ CI for each outcome were separately calculated for each trial, pooling data when needed, according to an intention-to-treat principle. The choice to use RRs was driven by the design of meta-analysis based on RCTs. Tau ${ }^{2}$ was used to define the variance between studies. The difference in the estimates of treatment effect between the treatment groups for each hypothesis was tested using the two-sided $z$ test with statistical significance considered at $p$ value $<0.05$. The homogeneity assumption was checked 
with the $Q$ test with a degree of freedom (df) equal to the number of analyzed studies minus 1 . The heterogeneity was measured by the $I^{2}$ metric, which describes the percentage of total variation across studies that is due to heterogeneity rather than chance. $I^{2}$ was calculated as:

$$
I^{2}=100 \% \AA \sim(\mathrm{Q}-\mathrm{df}) / \mathrm{Q}
$$

where $Q$ is Cochran's heterogeneity statistic and $\mathrm{df}$ is degrees of freedom. A value of $0 \%$ indicates no observed heterogeneity, and larger values show increasing heterogeneity. We decided a priori to analyze all the outcomes according to the following categories when possible: HME vs $\mathrm{HH}, \mathrm{HME}$ vs $\mathrm{HH}$ with heated wire and HME vs $\mathrm{HH}$ with non-heated wire.

Weighted random-effect meta-regression analysis was performed to test the relationship between the effect size on each considered outcome and the following covariates, with each one analysed separately: duration of MV, pneumonia incidence, intensive care unit (ICU) length of stay, percentage of respiratory diagnoses at ICU admission, simplified acute physiology score (SAPS), age and acute physiology and chronic health evaluation II (APACHE II) score.

Analyses were conducted with OpenMetaAnalyst (version 6) and SPSS version 20 (IBM SPSS). Weighted linear regression was used to evaluate potential publication bias, with the natural $\log$ of the $R R$ as the dependent variable and the inverse of the total sample size as the independent variable. This is a modified Macaskill test that gives more balanced type I error rates in the tail probability areas in comparison to other publication bias tests [8].

\section{Results}

\section{Study selection}

We identified 1349 references and excluded 1266 after screening titles and abstracts. We analyzed 77 articles in full paper format. We excluded 59 references [9-65] and 18 references fulfilled our search criteria [66-83]. Figure 1 shows the study selection process.

\section{Characteristics of included studies}

These 18 RCTs included 2442 adult critically ill patients. The main characteristics of the included studies are reported in Table 1.

\section{Systematic errors of included studies}

None of the included trials had a low risk of bias. The random sequence generation was adequate in seven studies [75, 78-83], adequate allocation concealment was present in three studies [77-79] and adequate blinding was present in two studies [75, 76]. Complete outcome data were reported from 10 studies [66-70, 73-76, 80-83]. Ten

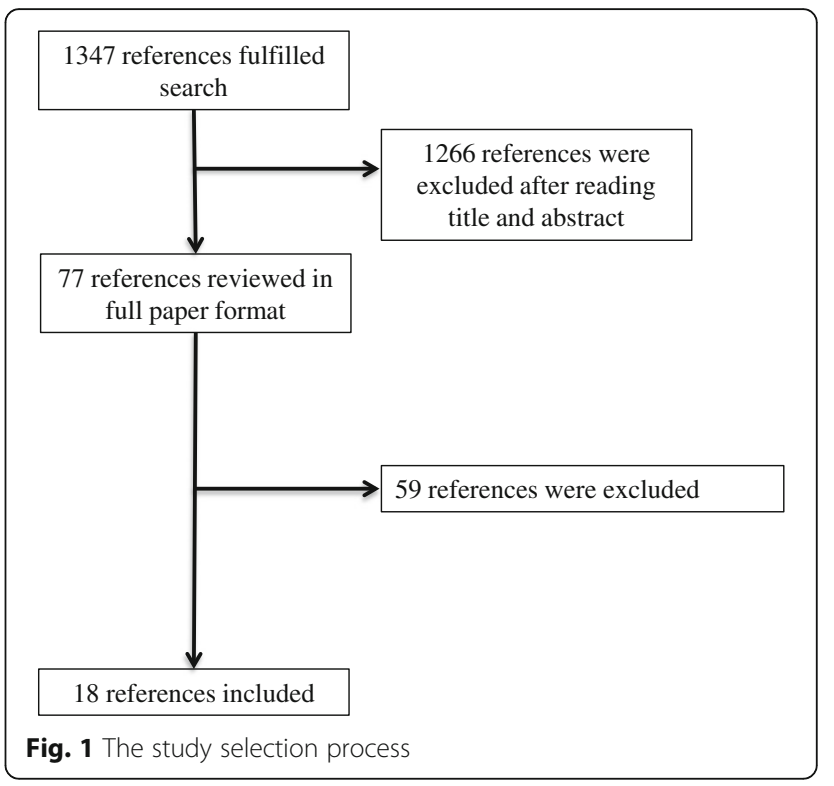

studies reported no imbalance in baseline characteristics [66-71, 73, 76, 79, 81]. The quality assessment for each RCT is reported in Additional file 1.

\section{Primary outcome}

The incidence of artificial airway occlusion was not different in patients treated with HMEs and HHs (Fig. 2) $(\mathrm{RR}=1.853$; 95\% CI 0.792-4.338). Artificial airway occlusion incidence was not different when comparing HMEs with $\mathrm{HHs}$ with heated wire $(\mathrm{RR}=0.379 ; 95 \% \mathrm{CI}$ 0.140-1.384) (Fig. 3, upper panel). However, airway occlusion was higher with HMEs compared with $\mathrm{HHs}$ with non-heated wire ( $\mathrm{RR}=3.776$; 95\% CI 1.560-9.143) (Fig. 3, lower panel), but there were no differences between hydrophobic and hygroscopic HMEs compared with HHs (Additional file 2).

\section{Secondary outcomes}

The incidence of pneumonia was not different in patients treated with HMEs and HHs (Fig. 4) $(\mathrm{RR}=932$; 95\% CI 0.730-1.190). Incidence of pneumonia was not different when comparing HMEs and $\mathrm{HHs}$ with heated wire ( $R R=0.997 ; 95 \%$ CI 0.642-1.548), with significant inhomogeneity $\left(I^{2}=54 \% ; p=0.042\right)$ (Fig. 5 , upper panel), neither was it different with $\mathrm{HHs}$ with non-heated wire $(\mathrm{RR}=0.756$; 95\% CI 0.479-1.193) (Fig. 5, lower panel).

Mortality was not different in patients treated with HMEs and HHs (Fig. 6, upper panel) $(\mathrm{RR}=1.023$; 95\% CI 0.878-1.192). Mortality was comparable in patients treated with HMEs and HHs with heated wire (RR = 0.947; 95\% CI 0.723-1.241) (Fig. 6, middle panel). We did not find differences in mortality when comparing HMEs and $\mathrm{HHs}$ with non-heated wire $(\mathrm{RR}=1.186 ; 95 \% \mathrm{CI}$ 0.852-1.650) (Fig. 6, lower panel). 


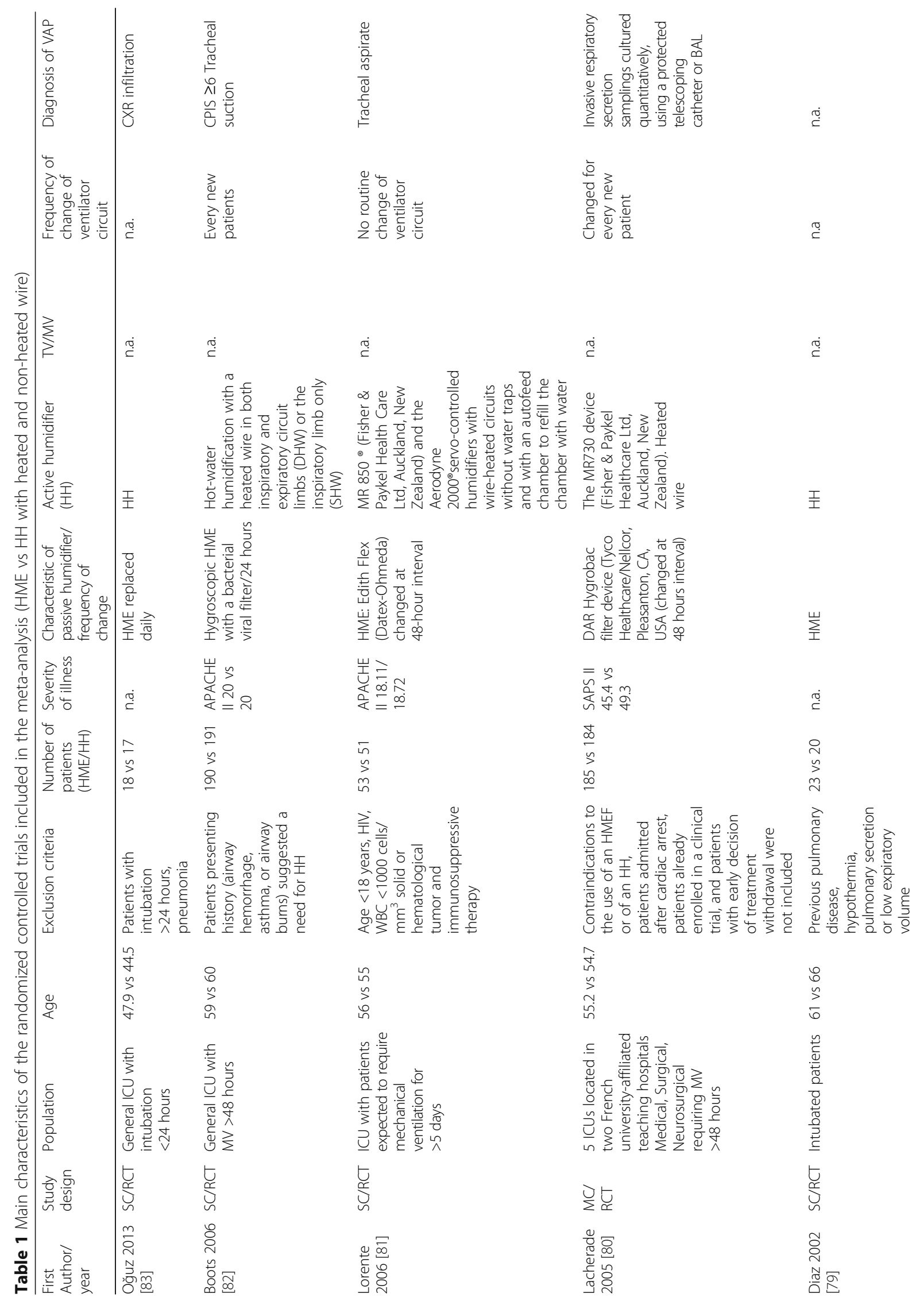




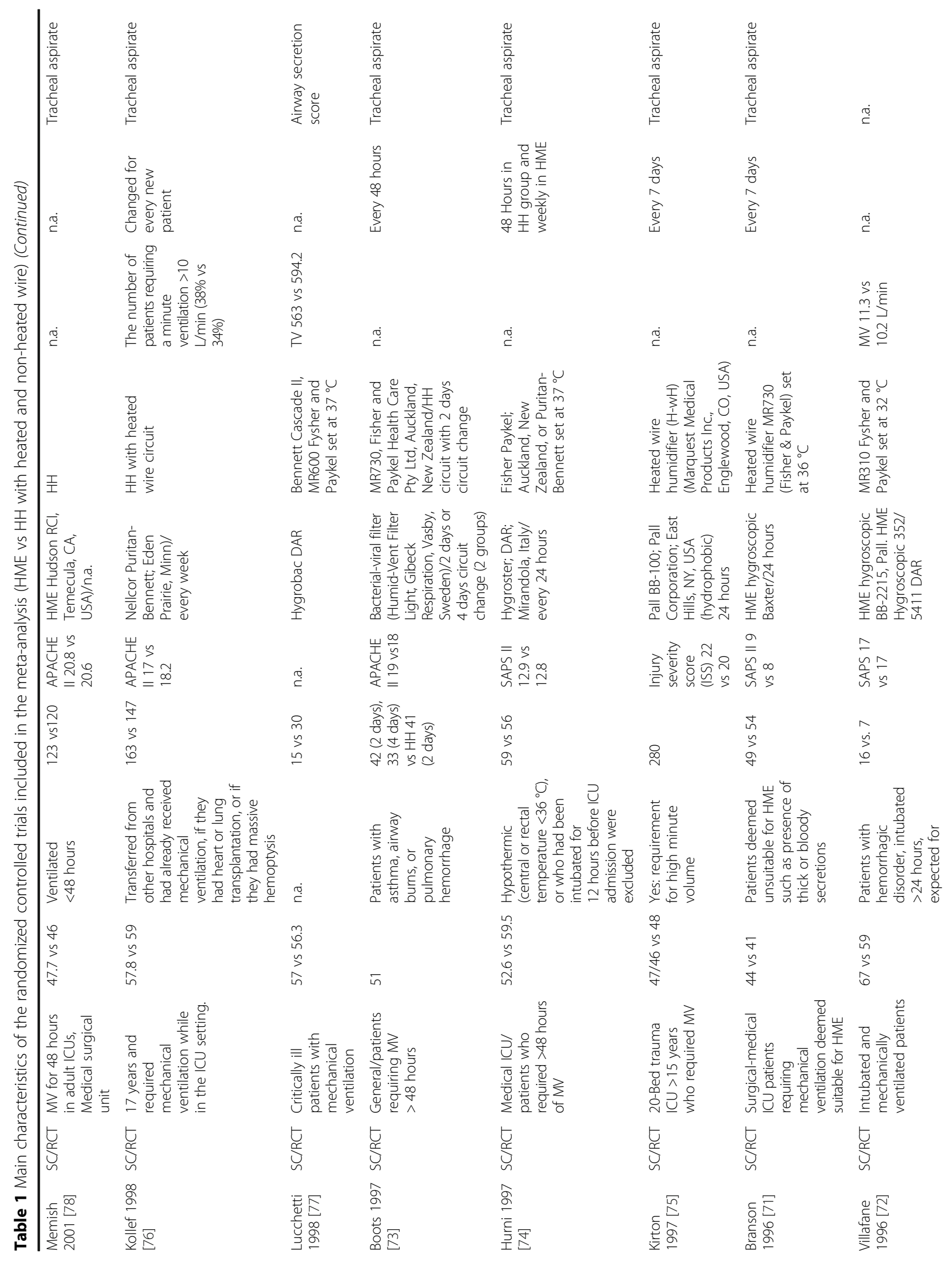




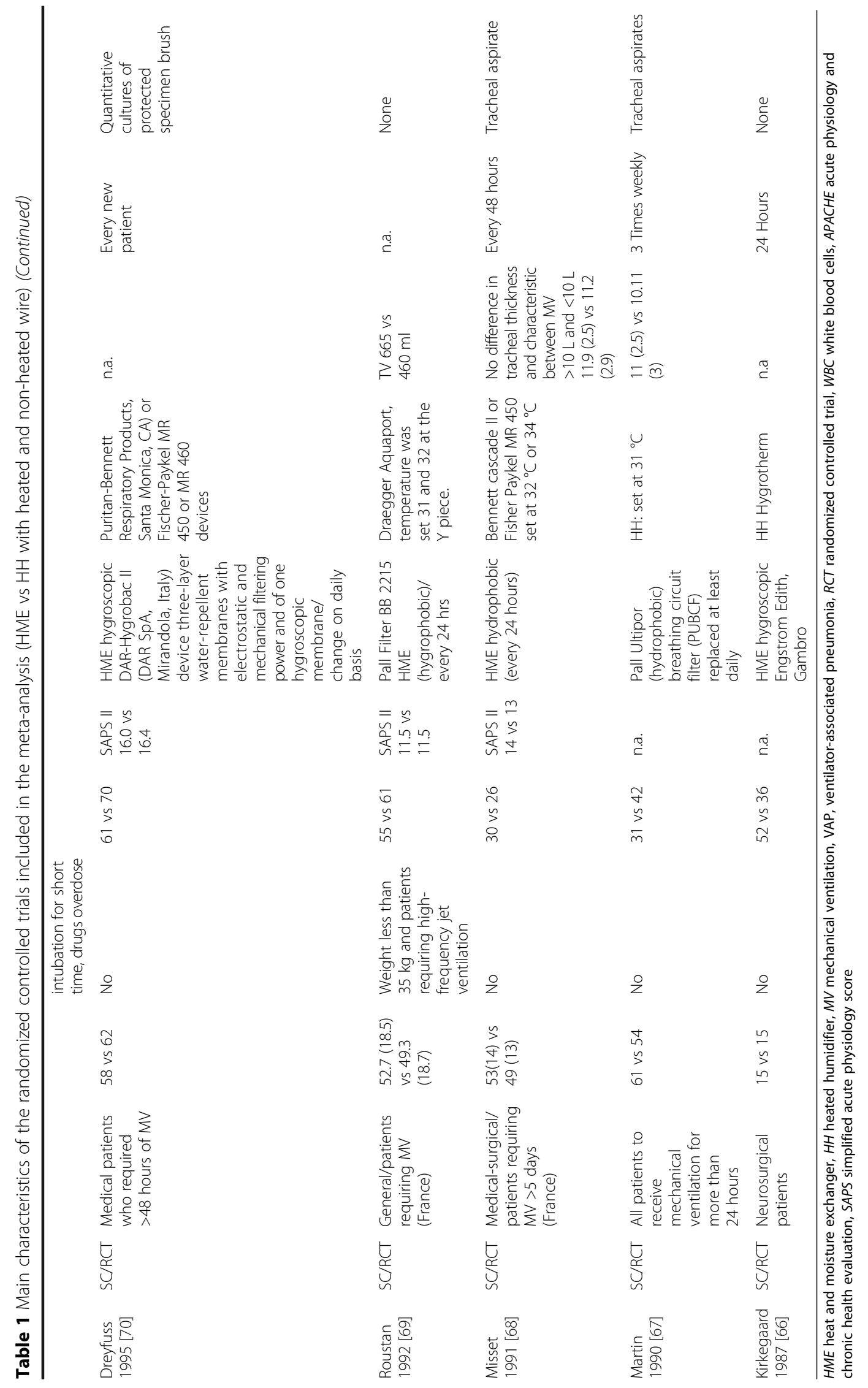




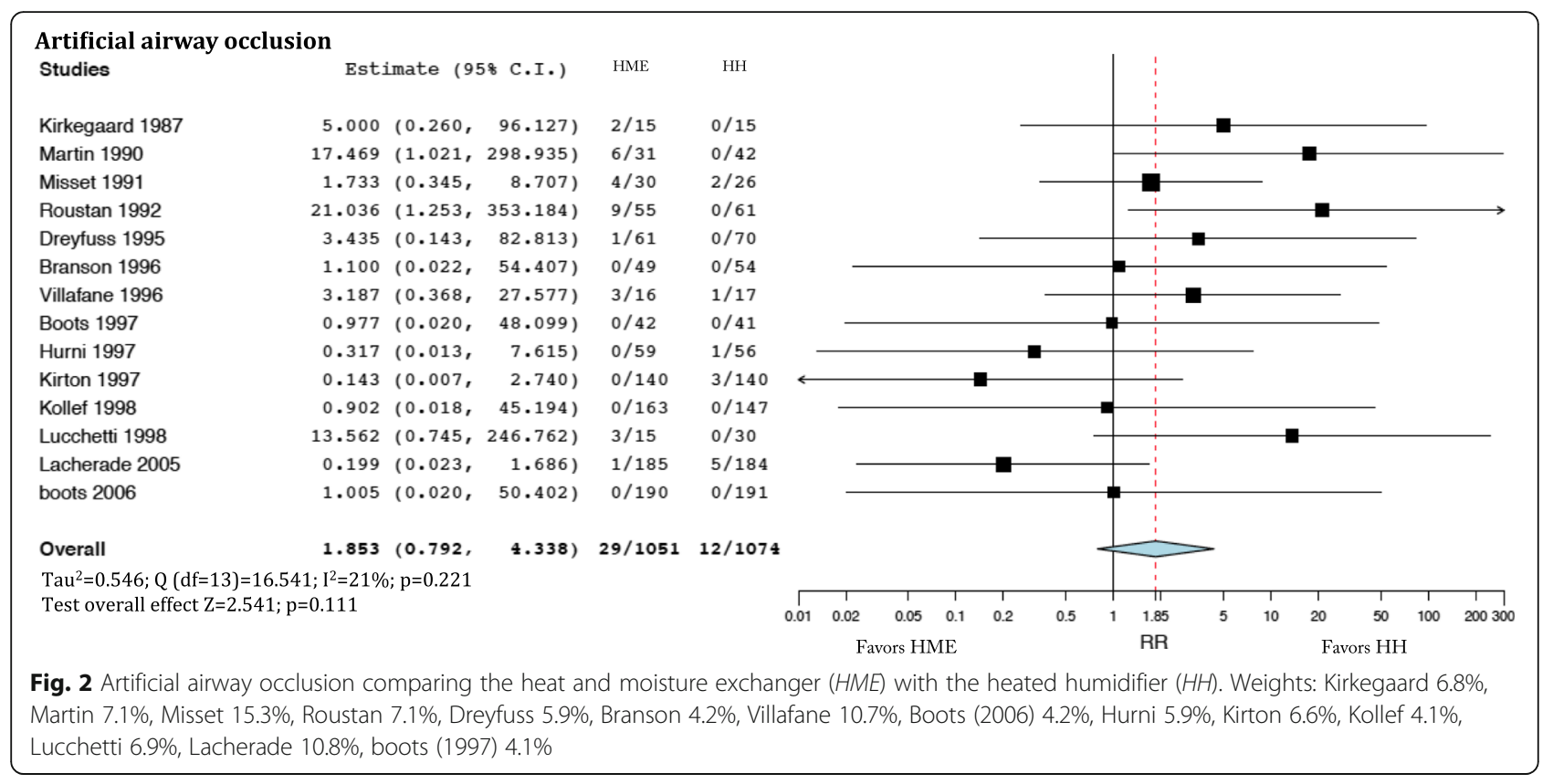

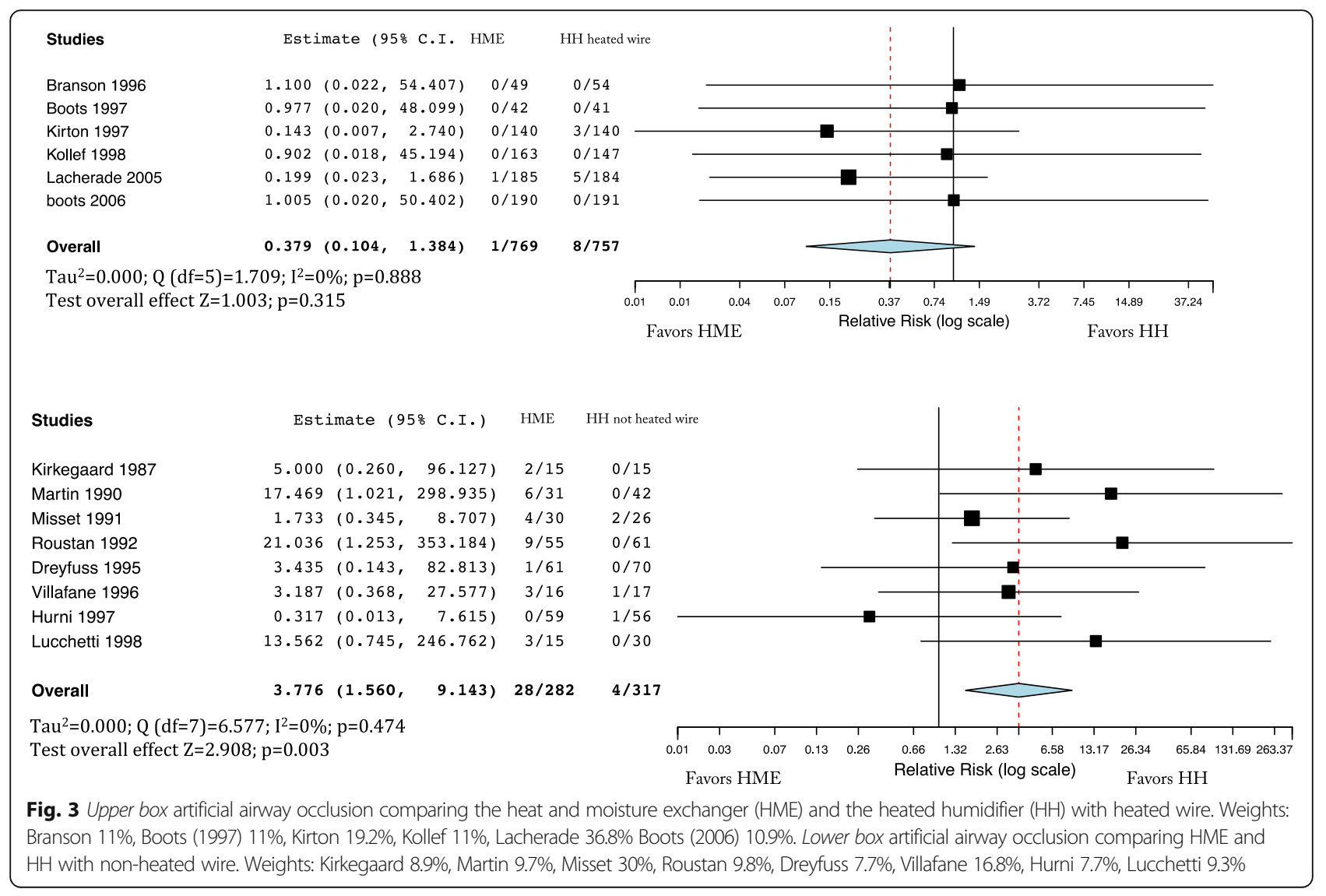




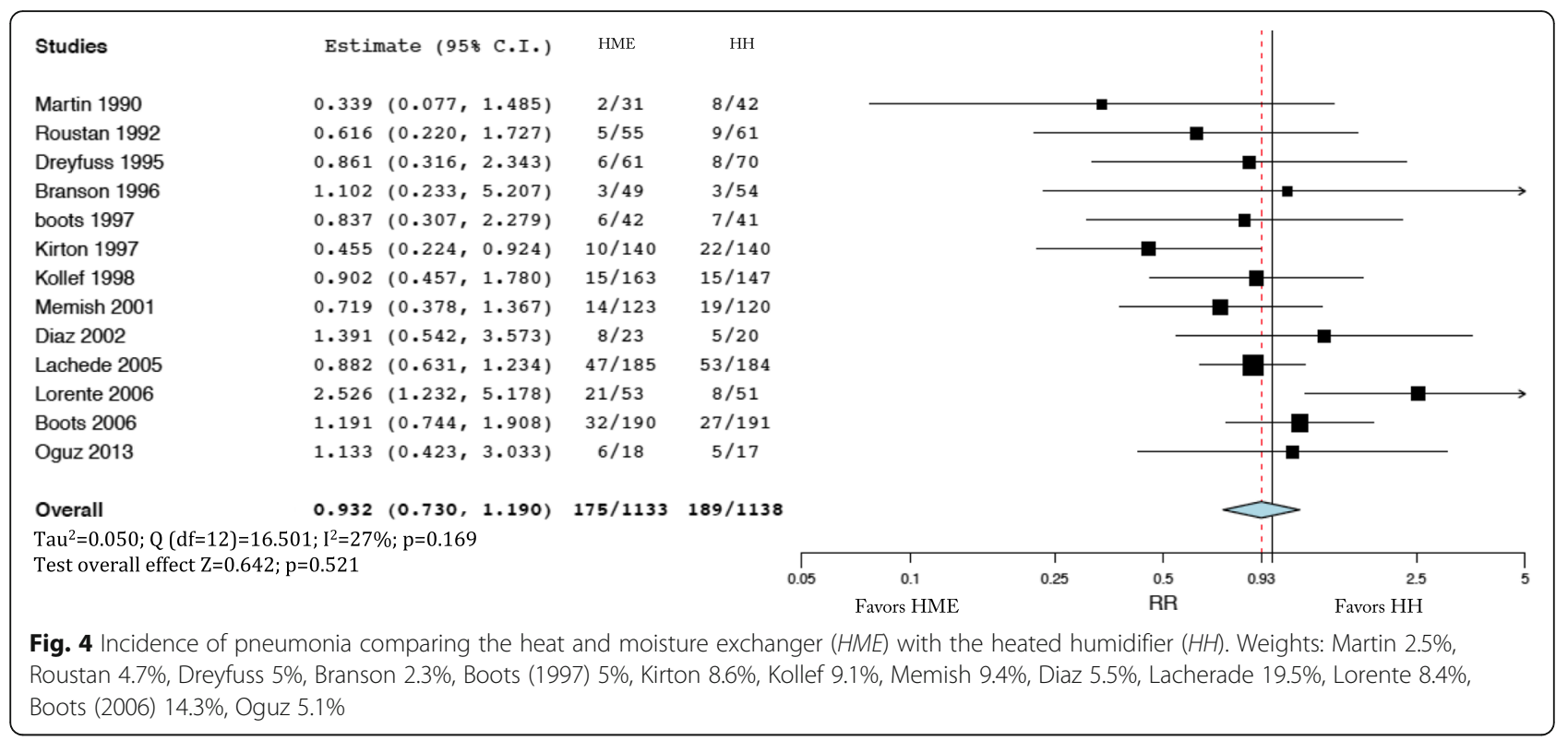

\section{Meta-regression analysis}

The effect size in the treatment group on artificial airway occlusion was influenced by the percentage of patients with pneumonia included in the study $(\beta=-0.058$; $p=0.027$; favoring HMEs in studies with high prevalence of pneumonia), and a trend was observed for the duration of MV ( $\beta=-0.108 ; p=0.054$; favoring HMEs in studies with longer MV time) (Fig. 7). No other significant associations with the effect size on any outcome measure were observed for the other clinical variables (see Additional file 3).

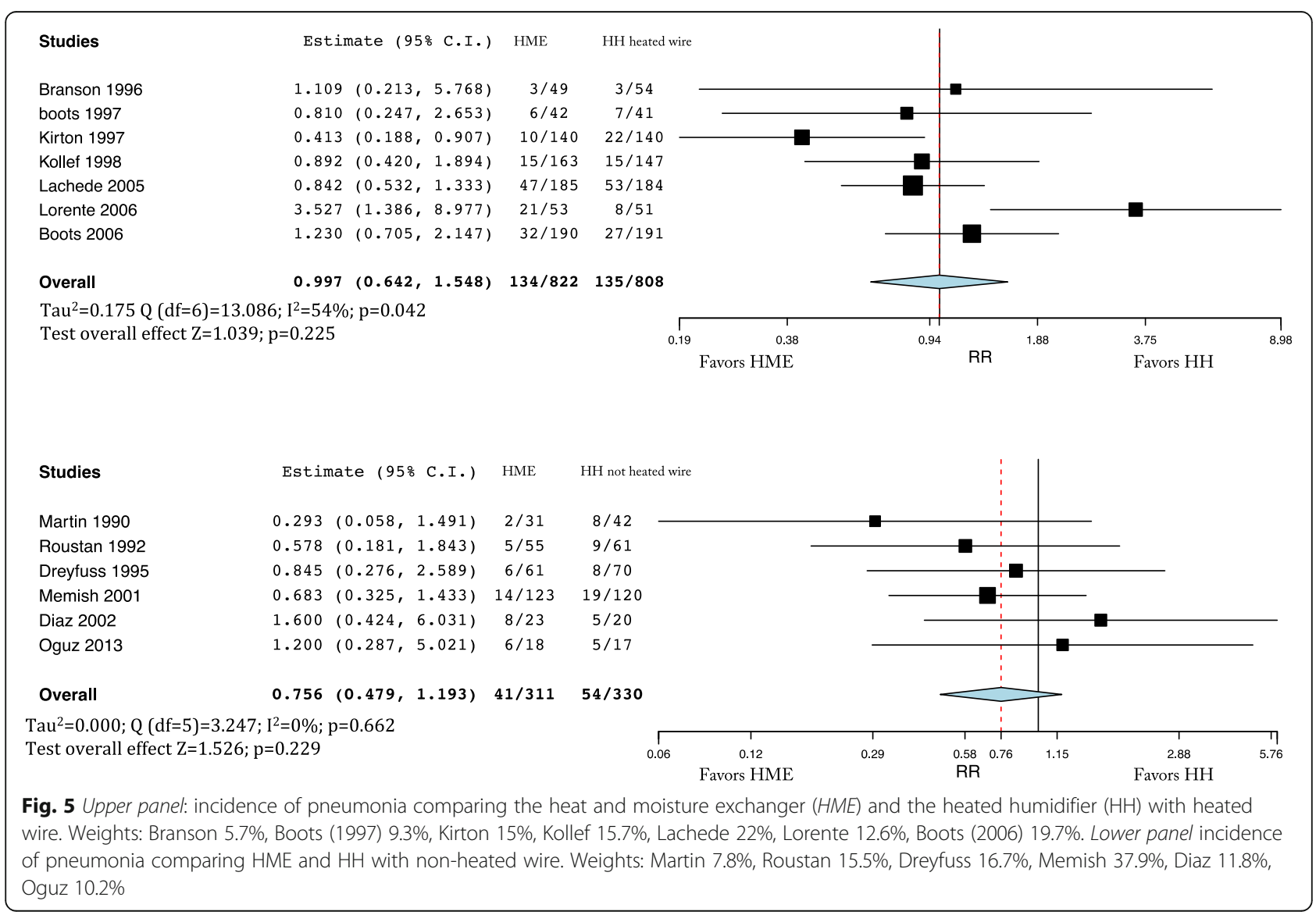




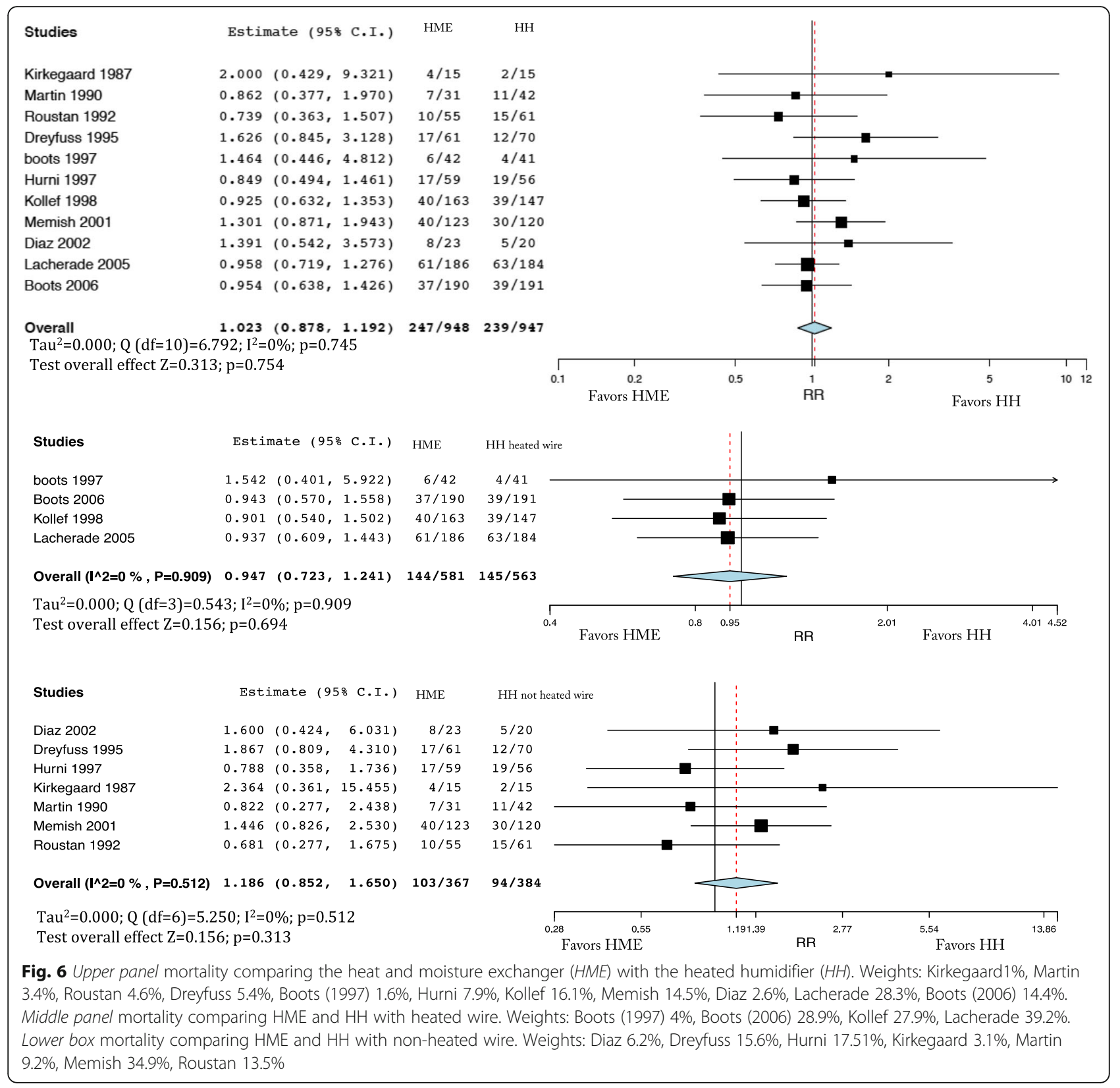

\section{Discussion}

In this systematic review and meta-analysis, we found: (1) no significant difference in artificial airway occlusion, pneumonia or mortality between HMEs and HHs, (2) no effect of $\mathrm{HHs}$ with and without heated wire compared to HMEs; however $\mathrm{HHs}$ with non-heated wire had the lower RR for artificial airway occlusion compared with HME, and (3) independently from the HH type, an advantage of HMEs in airway occlusion incidence was observed in studies with high incidence of pneumonia, and a trend toward favoring HMEs was observed for studies with prolonged MV. To our knowledge, this is the first systematic review performed (1) by dividing RCTs according to HHs with heated and non-heated wire and (2) including a meta-regression analysis on the potential effects of clinical variables on the efficacy of the two devices.

According to the American Association for Respiratory Care (AARC) guidelines, HHs should provide an absolute humidity level of between 33 and $44 \mathrm{mgH} 2 \mathrm{O} / \mathrm{L}$, whereas HMEs should provide a minimum humidity level of $30 \mathrm{mgH} 2 \mathrm{O} / \mathrm{L}$ [1]. HHs may produce insufficient heat and humidification when the temperature is improperly selected or pre-set at a non-adjustable level rather than at the clinical setting [1]. However, insufficient heat and humidification may occur with HMEs too [1]. 

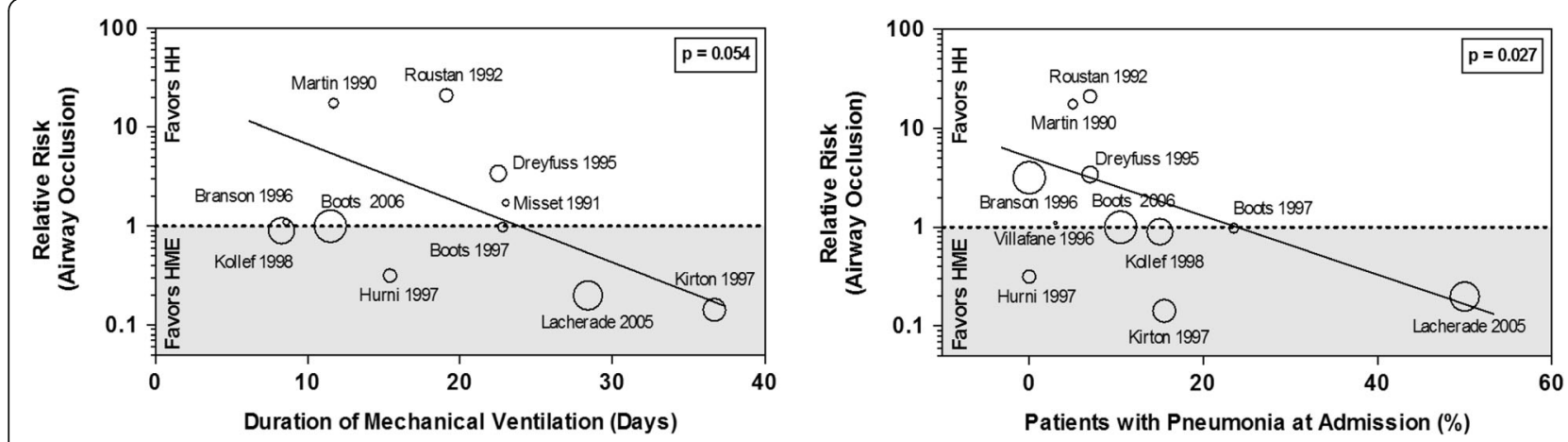

Fig. 7 Meta-regression on artificial airway occlusion including duration of mechanical ventilation $(\beta=2.637 ; p=0.054)$ and pneumonia ( $\beta=1.794$; $p=0.012$ ) as covariate. HME heat and moisture exchanger, HH heated humidifier

Only $37 \%$ of HMEs have been found to meet the standard criteria advocated by the AARC guidelines [1]. Insufficient airway humidification may lead to an increase in tracheal tube occlusion, a serious adverse event that may occur in mechanically ventilated patients and requires timely intervention. In an RCT comparing HMEs and $\mathrm{HHs}$ with increasing minute ventilation, the authors found that after 72 hours the inner diameter of the endotracheal tube decreased by $2.5-6.5 \mathrm{~mm}$ when gas conditioning was performed using HMEs and by $1.5 \mathrm{~mm}$ with $\mathrm{HHs}$ [72]. A systematic review showed that in patients ventilated more than 48 hours, there is no difference in tracheal tube occlusion when comparing HMEs and HHs [84]. In this meta-analysis, we found no differences in the incidence of artificial airway occlusion, but stratifying the comparison according to the type of $\mathrm{HHs}$ we found less risk for airway occlusion in HHs without heated wire compared with HME. However, these data were not confirmed by the sub-analysis comparing hydrophobic and hygroscopic HMEs with HHs. Probably, the main determinants of artificial airway occlusion are the duration of mechanical ventilation and pneumonia, rather than humidifier type per se, even if a prolonged use of HME ( $<72$ hours) may increase this risk. Long-term invasive $\mathrm{MV}$ and the presence of ventilator-associated pneumonia (VAP) increased the risk of artificial airway occlusion threefold in one study [85] and twofold in another [86]. This is the first meta-analysis reporting a meta-regression of included studies in this field. Our meta-regression showed that in studies with high incidence of pneumonia and prolonged MV, the HMEs had a slight advantage in terms of the artificial airway occlusion.

Earlier models of HME were associated with an increased incidence of airway occlusion, which led to the exclusion of patients at high risk from the studies [86]. In contrast, trials using HMEs with enhanced intrinsic humidifying performance showed no difference in the incidence of airway occlusion [86]. A Cochrane review states that hydrophobic HMEs may reduce the risk of pneumonia and the use of an HME may increase artificial airway occlusion in certain subgroups of patients [4]. Our analysis includes more recently published studies. According to our meta-regression, the HME may reduce the risk of airway occlusion in selected patients affected by pneumonia.

Hess et al. concluded in their clinical practice guidelines that HMEs are associated with lower incidence of pneumonia compared with HHs [85]. However, there are concerns about the increased airway resistance and care of HME filters [85]. Kola et al. found a significant reduction in pneumonia using HMEs during MV, particularly when patients are ventilated for 7 days or more [86]. Hess et al. included studies published between 1990 and 1998 in their analysis of pneumonia [85]. Kola et al. reported the same results as Hess et al. but they only included one more study in their meta-analysis. Accordingly, the underlying mechanism of reduction in pneumonia may be due to the dryness of the ventilator circuit when using HMEs [85, 86]. Therefore, HMEs minimized the need for septic manipulations or aspirations of the airway/circuit and the circuit condensate $[85,86]$. Furthermore, the inclusion of more recent studies may have changed the results. Indeed, Siempos et al. did not find any superiority of HMEs compared to $\mathrm{HHs}$ in reducing pneumonia, mortality or morbidity [87]. The results of Siempos et al. were groundbreaking and in line with the RCTs published at that time. The inclusion of three further RCTs [80-82] with 870 patients dramatically changed the previous results. The Cochrane review by Kelly et al. included adult and pediatric patients treated with HMEs and HHs [4]. There was no overall effect on artificial airway occlusion, mortality, pneumonia or respiratory complications; however, the arterial partial pressure of carbon dioxide $\left(\mathrm{PaCO}_{2}\right)$ and minute ventilation were increased while body temperature was lower when HMEs were compared to $\mathrm{HHs}$ [4] in a meta-analysis including 18 RCTs and 2442 adult critically ill patients. In line with the available literature, we did not find any difference in artificial airway occlusion, pneumonia or mortality 
between HMEs and HHs, even if according to their nature, they have different characteristics. However, HMEs were found to increase the $\mathrm{PaCO}_{2}$ and work of breathing probably due to higher dead space, and to reduce the inner diameter of the endotracheal tube during prolonged MV [4]. Indeed, HME may negatively impact on ventilator function while increasing the dead space [11]. In spontaneously and assisted breathing patients, this requires increased minute ventilation and then the work of breathing, to maintain constant alveolar ventilation and $\mathrm{PaCO}_{2}$. In controlled $\mathrm{MV}$, the additional dead space of HMEs may reduce alveolar ventilation and increase $\mathrm{PaCO}_{2}$ [11]. This effect of $\mathrm{HME}$ dead space may be further exacerbated by protective ventilation at low tidal volume (VT) and by using HMEs with a larger dead space [11].

Humidification is mandatory during MV. Nowadays, the airway humidification is appropriate in the absence of any contraindications listed by the AARC guidelines, such as altered body temperature, airway thermal injury, under hydrated secretions, increased work of breathing, hypoventilation, condensation and airway dehydration [1]. Clear advantages in terms of clinical outcomes for different humidification devices are far from being demonstrated. The present meta-analysis reported no superiority of HMEs over HHs in term of clinical outcomes, with similar results even when stratifying the studies according to the type of $\mathrm{HH}$, while some advantage of HMEs might be possible in patients with pneumonia or those with a long MV time. The choice of humidifiers should be made according to the clinical context trying to avoid possible complications and reaching the appropriate performance at lower costs. However, to help clinicians make the correct choice between HHs and HMEs, further high-quality RCTs are needed to evaluate the incidence of respiratory complications other than pneumonia, gas exchange and work of breathing when comparing the $\mathrm{HH}$ and HME devices.

This systematic review and meta-analysis has several limitations that must be addressed. First, the quality of the included RCTs was relatively low and our conclusions may be limited by this point. Second, the diagnosis of pneumonia was differently defined across the studies and often mixed with VAP. Third, the definition of mortality varied between the studies: three studies reported the ICU mortality, two studies reported overall mortality, two studies reported hospital mortality, one studies reported mortality during MV and in four studies mortality was not reported. Fourth, we performed the metaanalyses of outcomes if reported by more than three RCTs. Fifth, as we found only one additional RCT published between 2006 and 2013, the present results may depend on the studies published before 2006. However, in contrast to previous reports we included a metaregression analyzing and interpreting data from a new point of view. Sixth, we found few studies reporting the effective tracheal tube lumen and most of them with provided a poor definition of pneumonia diagnosed at ICU admission. Seventh, we are not able to stratify the meta-analysis according to the baseline respiratory condition or inclusion criteria. This did not allow us to suggest the use of HMEs or HHs in different respiratory diseases.

New, prospective RCTs are needed in terms of assessing the effect of HHs vs HMEs in patients with respiratory failure due to pneumonia, on airway diameter, the amount of secretion and the occurrence of artificial airway obstruction and VAP.

\section{Conclusions}

In this meta-analysis including 18 RCTs and 2442 adult critically ill patients, we found no superiority of HMEs or $\mathrm{HHs}$, in terms of artificial airway occlusion, pneumonia and mortality. These results were also confirmed in the sub-analysis dividing $\mathrm{HHs}$ into heated and non-heated wire devices. However, HHs with non-heated wire had the lower RR for artificial airway occlusion compared with HMEs. A trend favoring HMEs was observed in studies including a high percentage of patients with pneumonia diagnosis at admission and those with prolonged MV. However, the choice of humidifiers should be made according to the clinical context, trying to avoid possible complications and reaching the appropriate performance at lower costs.

\section{Additional files}

Additional file 1: Quality assessment. Quality assessment of these studies included: 1) use of randomization sequence generation, 2) reporting and type of allocation concealment, 3) blinding, 4) reporting of incomplete outcome data, 5) comparability of the groups at baseline. $\mathrm{H}$ : high, L: low, U: unknown. (PDF 80 kb)

Additional file 2: Meta-regression. Meta-regressions for artificial airway occlusion, pneumonia and mortality. (PDF $411 \mathrm{~kb}$ )

Additional file 3: Meta-analyses for hydrophobic and hygroscopic HME vs HH for Artificial airway occlusion, mortality and Pneumonia. (PDF 231 kb)

\section{Abbreviations \\ AARC: American Association for Respiratory Care; APACHE II: Acute physiology and chronic health evaluation II; Cl: Confidence interval; HHs: Heated humidifiers; HMEs: Heat and moisture exchangers; ICU: Intensive care unit; MV: Mechanical ventilation; $\mathrm{PaCO}_{2}$ : Arterial partial pressure of carbon dioxide; RCTs: Randomized controlled trials; RR: Relative risk; SAPS: Simplified acute physiology score; VAP: Ventilator-associated pneumonia}

\section{Acknowledgements}

Not applicable.

Funding

The authors received no funding for this study.

Availability of data and materials Not applicable. 


\section{Authors' contributions}

$M V, D C, Y S, L B, A M E, P P$ and GS contributed substantially to the study design, data analysis and interpretation, and the writing of the manuscript. All authors read and approved the final manuscript.

\section{Competing interests}

The authors declare that they have no competing interests.

\section{Consent for publication}

Not applicable.

\section{Ethics approval and consent to participate}

Not applicable.

\section{Publisher's Note}

Springer Nature remains neutral with regard to jurisdictional claims in published maps and institutional affiliations.

\begin{abstract}
Author details
'Department of Neurosciences, Reproductive and Odonthostomatological Sciences, University of Naples "Federico II", Naples, Italy. ${ }^{2}$ Dipartimento di Emergenza - Urgenza, ASST Santi Paolo e Carlo; Dipartimento di Scienze della salute, Università degli Studi di Milano, Milan, Italy. ${ }^{3}$ Division of pulmonary and critical care medicine, Faculty of medicine Ramathibodi hospital, Mahidol University, 270 RAMA VI road, Bangkok 10400, Thailand. ${ }^{4}$ Department of Surgical Sciences and Integrated Diagnostics, AOU IRCCS San Martino- IST, University of Genoa, Genoa, Italy. ${ }^{5}$ Intensive Care Unit, Hospital Morales Meseguer, Murcia, Spain.
\end{abstract}

\section{Received: 25 July 2016 Accepted: 9 May 2017}

Published online: 29 May 2017

\section{References}

1. American Association for Respiratory Care, Restrepo RD, Walsh BK. Humidification during invasive and noninvasive mechanical ventilation: 2012. Respir Care. 2012;57(5):782-8.

2. Branson RD, Chatburn RL. Humidification of inspired gases during mechanical ventilation. Respir Care. 1993;38:461-8.

3. Lellouche F, Qader S, Taille S, Lyazidi A, Brochard L. Influence of ambient temperature and moisture ventilation on passive and active heat and moisture exchange. Respir Care. 2014;59(5):637-43.

4. Kelly M, Gillies D, Todd DA, Lockwood C. Heated humidification versus heat and moisture exchangers for ventilated adults and children. Cochrane Database Syst Rev. 2010;4:CD004711. doi:10.1002/14651858.CD004711.pub2.

5. Dixon-Woods M, Shaw RL, Agarwal S, Smith JA. The problem of appraising qualitative research. Qual Saf Health Care. 2004;13:223-5.

6. Denzin N, Riessman C. Narrative analysis. J Commun. 1995:45:177-84.

7. PRISMA guideline. http://www.prisma-statement.org/

8. Peters JL, Sutton AJ, Jones DR, Abrams KR, Rushton L. Comparison of two methods to detect publication bias in meta-analysis. JAMA. 2006;295(6):676-80.

9. Bissonnette B. Passive or active inspired gas humidification increases thermal steady-state temperatures in anesthetized infants. Anesth Analg. 1989;69(6):783-7.

10. Bissonette B, Sessler DI, La Flamme P. Passive and active inspired gas humidification in infants and children. Anesthesiology. 1989;71(3):350-4.

11. Campbell RS, Davis Jr K, Johannigman JA, Branson RD. The effects of passive humidifier dead space on respiratory variables in paralyzed and spontaneously breathing patients. Respir Care. 2000:45(3):306-12.

12. Deriaz H, Fiez N, Lienhart A. Comparative effects of a hygrophobic filter and a heated humidifier on intraoperative hypothermia. Ann Fr Anesth Reanim. 1992;11(2):145-9.

13. Girault C, Breton L, Richard J, Tamion F, Vandelet P, Aboab J, et al. Mechanical effects of airway humidification devices in difficult to wean patients. Crit Care Med. 2003;31(5):1306-11.

14. Goldberg ME, Epstein R, Rosenblum F, Larijani GE, Marr A, Lessin J, et al. Do heated humidifiers and heat and moisture exchangers prevent temperature drop during lower abdominal surgery? J Clin Anesth. 1992;4(1):16-20.

15. lotti GA, Olivei MC, Palo A, Galbusera C, Veronesi R, Comelli A, et al. Unfavorable mechanical effects of heat and moisture exchangers in ventilated patients. Intensive Care Med. 1997;23(4):399-405.
16. Le Bourdelles G, Mier L, Fiquet B, Djedaini K, Saumon G, Coste F, et al. Comparison of the effects of heat and moisture exchangers and heated humidifiers on ventilation and gas exchange during weaning trials from mechanical ventilation. Chest. 1996;110(5):1294-8.

17. Linko K, Honkavaara P, Nieminen MT. Heated humidification in major abdominal surgery. Eur J Anaesthesiol. 1984;1(3):285-91.

18. Maclntyre NR, Anderson HR, Silver RM, Schuler FR, Coleman RE. Pulmonary function in mechanically ventilated patients during 24-hour use of a hygroscopic condensor humidifier. Chest. 1983;84(5):560-4.

19. Martin C, Papazian L, Perrin G, Saux P, Gouin F. Preservation of humidity and heat of respiratory gases in patients with a minute ventilation greater than 10 L/min. Crit Care Med. 1994;22(11):1871-6.

20. Pelosi P, Solca M, Ravagnan I, Tubiolo D, Ferrario L, Gattinoni L. Effects of heat and moisture exchangers on minute ventilation, ventilatory drive, and work of breathing during pressure-support ventilation in acute respiratory failure. Crit Care Med. 1996;24(7):1184-8.

21. Ricard JD, Markowicz P, Djedaini K, Mier L, Coste F, Dreyfuss D. Bedside evaluation of efficient airway humidification during mechanical ventilation of the critically ill. Chest. 1999;115(6):1646-52.

22. Roustan JP, Kienlen J, Aubas S, Du Cailar J. Evaluation of an exchange filter on heat and humidity in long duration mechanical ventilation. Comparison with heated humidification. Ann Fr Anesth Reanim. 1989;8 Suppl:R275.

23. Thomachot L, Viviand X, Lagier P, Dejode JM, Albanese J, Martin C. Measurement of tracheal temperature is not a reliable index of total respiratory heat loss in mechanically ventilated patients. Crit Care. 2001;5(1):24-30.

24. Alagar R. Heated humidification reduces saline instillations, nebulized therapy, and cost in long term ventilated patients (abstract). American Journal of Respiratory and Critical Care Medicine. American Thoracic Society 2000 International Conference; May 5-10; Toronto, Canada. 2000; Vol. 161; 3 Suppl: A552.

25. Branson RD, Davis Jr K, Campbell RS, Johnson DJ, Porembka DT. Humidification in the intensive care unit: prospective study of a new protocol utilizing heated humidification and a hydroscopic condenser humidifier. Chest. 1993;104(6):1800-05.

26. Branson RD, Campbell RS, Johannigman JA, Ottaway M, Davis Jr K, Luchette FA, et al. Comparison of conventional heated humidification with a new active hygroscopic heat and moisture exchanger in mechanically ventilated patients. Respir Care. 1999;44(8):912-17.

27. Christiansen S, Renzing K, Hirche H, Reidemeister JC. Measurements of inspired air humidity as provided by different humidifiers. Anasthesiol Intensivmed Notfallmed Schmerzther. 1998;33(5):300-5.

28. Cohen IL, Weinberg PF, Fein IA, Rowinski GS. Endotracheal tube occlusion associated with the use of heat and moisture exchangers in the intensive care unit. Crit Care Med. 1988;16(3):277-9.

29. Conti G, De Blasi RA, Rocco M, Pelaia P, Antonelli M, Bufi M, et al. Effects of the heat-moisture exchangers on dynamic hyperinflation of mechanically ventilated COPD patients. Intensive Care Med. 1990;16(7):441-3.

30. Dias MD, Pellacine EN, Zechineli CA. The new system of gaseous mixture humidification and heating of respirators: comparative study. Rev Assoc Med Bras. 1993;39(4):207-12.

31. Dias MD, Pellacine EN, Zechineli CA. Bacterial aerosol generated by mechanical ventilators: comparative study. Rev Assoc Med Bras. 1997;43(1):15-20.

32. Fujita Y, Imanaka H, Fujino Y, Takeuchi M, Tomita T, Mashimo T, Nishimura M. Effect of humidifying devices on the measurement of tidal volume by mechanical ventilators. J Anesth. 2006;20(3):166-72.

33. Jaber S, Pigeot J, Fodil R, Maggiore S, Harf A, Isabey D, et al. Long-term effects of different humidification systems on endotracheal tube patency: evaluation by the acoustic reflection method. Anesthesiology. 2004;100(4):782-8.

34. Johnson PA, Raper RF, Fisher MDM. The impact of heat and moisture exchanging humidifiers on work of breathing. Anaesth Intensive Care. 1995;23(6):697-701.

35. Kranabetter R, Leier M, Kammermeier D, Just HM, Heuser D. The effects of active and passive humidification on ventilation-associated nosocomial pneumonia. Anaesthesist. 2004;53(1):29-35.

36. Lellouche F, Qader S, Taille S, Lyazidi A, Brochard L. Under-humidification and over-humidification during moderate induced hypothermia with usual devices. Intensive Care Med. 2006;32(7):1014-21.

37. Luchetti M, Pigna A, Gentili A, Marraro G. Evaluation of the efficiency of heat and moisture exchangers during paediatric anaesthesia. Paediatr Anaesth. 1999:9(1):39-45.

38. MacLeod R, Bucknall T. Mechanical ventilation with heated humidifiers or with heat and moisture exchangers with microbiological filters did not reduce ventilator associated pneumonia in adults. Evid Based Nursing. 2006;9(3):82. 
39. Martin C, Papazian L, Perrin G, Bantz P, Gouin F. Performance evaluation of three vaporizing humidifiers and two heat and moisture exchangers in patients with minute ventilation > $10 \mathrm{~L} / \mathrm{min}$. Chest. 1992;102(5):1347-50.

40. Martin C, Thomachot L, Quinio B, Viviand X, Albanese J. Comparing two heat and moisture exchangers with one vaporizing humidifier in patients with minute ventilation greater than $10 \mathrm{~L} / \mathrm{min}$. Chest. 1995;107(5):1411-5.

41. McEvoy MT, Carey TJ. Shivering and rewarming after cardiac surgery: comparison of ventilator circuits with humidifier and heated wires to heat and moisture exchangers. Am J Crit Care. 1995;4(4):293-9.

42. Nakagawa NK, Macchione M, Petrolino HM, Guimaraes ET, King M, Saldiva $\mathrm{PH}$, et al. Effects of a heat and moisture exchanger and a heated humidifier on respiratory mucus in patients undergoing mechanical ventilation. Crit Care Med. 2000;28(2):312-7.

43. Prat G, Renault A, Tonnelier JM, Goetghebeur D, Oger E, Boles JM, et al. Influence of the humidification device during acute respiratory distress syndrome. Intensive Care Med. 2003;29(12):2211-5.

44. Prin S, Chergui K, Augarde R, Page B, Jardin F, Vieillard- Baron A. Ability and safety of a heated humidifier to control hypercapnic acidosis in severe ARDS. Intensive Care Med. 2002;28(12):1756-60.

45. Rathgeber J, Henze D, Zuchner K. Air conditioning with a high-performance HME (heat and moisture exchanger) - an effective and economical alternative to active humidifiers in ventilated patients. A prospective and randomized clinical study. Anaesthesist. 1996;45(6):518-25.

46. Rathgeber J, Betker T, Zuchner K. Measurement of water vapour pressure in the airways of mechanically ventilated patient using different types of humidifier. Anasthesiol Intensivmed Notfallmed Schmerzther. 2001;36(9):560-5.

47. Schiffmann H, Rethgeber J, Singer D, Harms K, Bolli A, Zuchner K. Airway humidification in mechanically ventilated neonates and infants: A comparative study of a heat and moisture exchanger vs. a heated humidifier using a new fast-response capacitive humidity sensor. Crit Care Med. 1997;25(10):1755-60.

48. Takumi Y, Aochi O. Effect of emphysematous expansion and humidification on the intrapulmonary gas exchange. Anaesthesist. 1970;19(10):373-83.

49. Thomachot L, Viviand X, Arnaud S, Vialet R, Albanese J, Martin C. Preservation of humidity and heat of respiratory gases in spontaneously breathing, tracheostomized patients. Acta Anaesthesiol Scand. 1998;42(7):841-4.

50. Wilmshurst JM, Rahman MA, Shah V, Elton P, Long D, Martin N. The heat moisture exchange device (HME) in neonatal ventilation. Am J Perinatol. 1999;16(1):13-6.

51. Boyer A, Vargas F, Hilbert G, Gruson D, Mousset-Hovaere M, Castaing Y, Dreyfuss D, Ricard JD. Small dead space heat and moisture exchangers do not impede gas exchange during noninvasive ventilation: a comparison with a heated humidifier. Intensive Care Med. 2010;36(8):1348-54.

52. Arieli R, Daskalovic Y, Ertracht O, Arieli Y, Adir Y, Abramovich A, Halpern P. Flow resistance, work of breathing of humidifiers, and endotracheal tubes in the hyperbaric chamber. Am J Emerg Med. 2011;29(7):725-30.

53. Thille AW, Bertholon JF, Becquemin MH, Roy M, Lyazidi A, Lellouche F, Pertusini E, Boussignac G, Maître B, Brochard L. Aerosol delivery and humidification with the Boussignac continuous positive airway pressure device. Respir Care. 2011;56(10):1526-32.

54. Retamal J, Castillo J, Bugedo G, Bruhn A. Airway humidification practices in Chilean intensive care units. Rev Med Chil. 2012;140(11):1425-30.

55. Tonnelier A, Lellouche F, Bouchard PA, L'Her E. Impact of humidification and nebulization during expiratory limb protection: an experimental bench study. Respir Care. 2013;58(8):1315-22.

56. Schena E, Saccomandi P, Cappelli S, Silvestri S. Mechanical ventilation with heated humidifiers: measurements of condensed water mass within the breathing circuit according to ventilatory settings. Physiol Meas. 2013;34(7):813-21.

57. Ehrmann S, Roche-Campo F, Sferrazza Papa GF, Isabey D, Brochard L, Apiou-Sbirlea G. REVA research network. Aerosol therapy during mechanical ventilation: an international survey. Intensive Care Med. 2013;39(6):1048-56.

58. Alonso-Iñigo JM, Almela A, Albert A, Carratalá JM, Fas MJ. Active humidification with Boussignac CPAP: in vitro study of a new method. Respir Care. 2013;58(4):647-54

59. Schena E, Quaranta A, Saccomandi P, Silvestri S. Performances of heated humidifiers in mechanical ventilation: a preliminary intra-breath analysis. Conf Proc IEEE Eng Med Biol Soc. 2013;2013:934-7.

60. Lellouche F, Pignataro C, Maggiore SM, Girou E, Deye N, Taillé S, Fischler M, Brochard L. Short-term effects of humidification devices on respiratory pattern and arterial blood gases during noninvasive ventilation. Respir Care. 2012;57(11):1879-86.
61. Schena E, Saccomandi P, Ramandi C, Silvestri S. A novel control strategy to improve the performances of heated wire humidifiers inartificial neonatal ventilation. Physiol Meas. 2012;33(7):1199-211.

62. Morán I, Cabello B, Manero E, Mancebo J. Comparison of the effects of two humidifier systems on endotracheal tube resistance. Intensive Care Med. 2011;37(11):1773-9.

63. Schena E, De Paolis E, Silvestri S. Gas pre-warming for improving performances of heated humidifiers in neonatal ventilation. Conf Proc IEEE Eng Med Biol Soc. 2011;2011:1205-8.

64. Lorente L, Blot $\mathrm{S}$, Rello J. New issues and controversies in the prevention of ventilator-associated pneumonia. Am J Respir Crit Care Med. 2010;182(7):870-6.

65. Verta A, Schena E, Silvestri S. Mathematical model and minimal measurement system for optimal control of heated humidifiers in neonatal ventilation. Med Eng Phys. 2010;32(5):475-81.

66. Kirkegaard L, Andersen BN, Jensen S. Moistening of inspired air during respirator treatment. Comparison between the water-bath evaporator and hygroscopic moisture heat exchanger. Ugeskr Laeger. 1987;149(3):152-5.

67. Martin C, Perrin G, Gevaudan MJ, Saux P, Gouin F. Heat and moisture exchangers and vaporizing humidifiers in the intensive care unit. Chest 1990;97(1):144-9.

68. Misset B, Escudier B, Rivara D, Leclerca B, Nitenberg G. Heat and moisture exchanger vs heated humidifier during long-term mechanical ventilation. $A$ prospective randomized study. Chest. 1991;100(1):160-3.

69. Roustan JP, Kienlen J, Aubas P, Aubas S, du Cailar J. Comparison of hydrophobic heat and moisture exchangers with heated humidifier during prolonged mechanical ventilation. Intensive Care Med. 1992;18(2):97-100.

70. Dreyfuss D, Djedaini K, Gros I, Mier L, LeBourdelles G, Cohen Y, et al. Mechanical ventilation with heated humidifiers or heat and moisture exchangers: effects on patient colonization and incidence of nosocomial pneumonia. Am J Respir Crit Care Med. 1995;151(4):986-92.

71. Branson RD, Davis Jr K, Brown R, Rashkin M. Comparison of three humidification techniques during mechanical ventilation: patient selection, cost and infections considerations. Respir Care. 1996;41(9):809-16.

72. Villafane MC, Cinnella G, Lofaso F, Isabey D, Harf A, Lemaire F, et al. Gradual reduction of endotracheal tube diameter during mechanical ventilation via different humidification devices. Anesthesiology. 1996;85(6):1341-9.

73. Boots R, Howe S, George N, Harris F, Faoagali J. Clinical utility of hygroscopic heat and moisture exchangers in intensive care patients. Crit Care Med. 1997;25(10):1707-12.

74. Hurni J, Feihl F, Lazor R, Leuenberger P, Perret C. Safety of combined heat and moisture exchanger filters in long term mechanical ventilation. Chest. 1997;111(3):686-91.

75. Kirton O, De Haven B, Morgan J, Morejon O, Civetta J. A prospective, randomised comparison of an in-line heat moisture exchange filter and heated wire humidifiers: rates of ventilator-associated early-onset (community-acquired) or late-onset (hospital-acquired) pneumonia and incidence of endotracheal tube occlusion. Chest. 1997;112(4):1055-9.

76. Kollef MH, Shapiro SD, Boyd V, Silver P, Von Harz B, Trovillion E, et al. A randomized clinical trial comparing an extended-use hygroscopic condenser humidifier with heated-water humidification in mechanically ventilated patients. Chest. 1998;113(3):759-67.

77. Luchetti M, Stuani A, Castelli G, Marraro G. Comparison of three different humidification systems during prolonged mechanical ventilation. Minerva Anestesiol. 1998;64(3):75-81.

78. Memish ZA, Oni GA, Djazmati W, Cunningham G, Mah MW. A randomized clinical trial to compare the effects of a heat and moisture exchanger with a heated humidifying system on the occurrence rate of ventilator-associated pneumonia. Am J Infect Control. 2001;29(5):301-5.

79. Diaz RB, Barbosa DA, Bettencourt AR, Vianna LAC, Gir E, Guimaraes T. Evalution [sic] the use of hygroscopic humidifier filters to prevent nosocomial pneumonia. Acta Paulista de Enfermagem. 2002;15(4):32-44.

80. Lacherade JC, Auburtin M, Cerf C, Van de Louw A, Soufir L, Rebufat Y, et al. Impact of humidification systems on ventilator-associated pneumonia: a randomized multicenter trial. Am J Respir Crit Care Med. 2005;172(10): 1276-82.

81. Lorente L, Lecuona M, Jimenez A, Mora ML, Sierra A. Ventilator-associated pneumonia using a heated humidifier or a heat and moisture exchanger: a randomized controlled trial. Crit Care. 2006;10(4):R116.

82. Boots RJ, George N, Faoagali JL, Druery J, Dean K, Heller RF. Double-heater-wire circuits and heat-and-moisture exchangers and the risk of ventilator-associated pneumonia. Crit Care Med. 2006;34(3):687-93. 
83. Oguz S, Deger I. Ventilator-associated pneumonia in patients using HME filters and heated humidifiers. Ir J Med Sci. 2013;182(4):651-5.

84. Bench S. Humifification in thr long-term ventilated patients; a systematic review. Intens Crit Care Nurs. 2033:19:75-84.

85. Hess DR, Kallstrom TJ, Mottram CD, et al. American Association for Respiratory Care are of the ventilator circuit and its relation to ventilator associated pneumonia. Respir Care. 2003;48:869-79.

86. Kola A, Eckmanns T, Gaistmeier P. Efficacy of heat and moisturing exchangers in preventing ventilator-associated pneumonia: meta-analysis of randomized controlled trials. Intensive Care Med. 2005;31:5-11.

87. Siempos II, Vardakas KZ, Kopterides P, Falagas ME. Impact of passive humidifcation on clinical outcomes of mechanically ventilated patients: a meta-analysis of randomized controlled trials. Crit Care Med. 2007;35:2843-51.

Submit your next manuscript to BioMed Central and we will help you at every step:

- We accept pre-submission inquiries

- Our selector tool helps you to find the most relevant journal

- We provide round the clock customer support

- Convenient online submission

- Thorough peer review

- Inclusion in PubMed and all major indexing services

- Maximum visibility for your research

Submit your manuscript at www.biomedcentral.com/submit
Biomed Central 